() 2020 ФГБУ «НМИЦ ДГОИ им. Дмитрия Рогачева» Минздрава России

Поступила 15.06.2020 Принята к печати 25.07.2020

Контактная информация: Андреева Наталья Александровна, врач-детский онколог отделения клинической онкологии, младший научный сотрудник отдела исследований эмбриональных опухолей и лаборатории молекулярной онкологии ФГБУ «НМИЦ ДГОИ им. Дмитрия Рогачева» Минздрава России Адрес: 117997, Москва, ул. Саморы Машела, 1 E-mail: andreeva7930bk.ru

(c) 2020 by «D. Rogachev NMRCPHOl» Received 15.06.2020 Accepted 25.07.2020

Correspondence: Natalya A. Andreeva a pediatric oncologist at the Department of Clinical Oncology, a junior researcher at the Department of Embryonal Tumour Research and the Laboratory of Molecular

Oncology, Dmitry Rogachev Nationa

Medical Research Center of Pediatric Hematology, Oncology and Immunology,

Ministry of Healthcare of the Russian Federation

Address: 1 Samory Mashela St. Moscow 117997, Russia E-mail: andreeva793@bk.ru
DOI: 10.24287/1726-1708-2020-19-4-94-101

Аллогенная трансплантация

гемопоэтических стволовых клеток при альвеолярной рабдомиосаркоме. Описание первого опыта гаплоидентичной трансплантации в клинической практике

\author{
Н.А. Андреева, Е.А. Друй, Ю.М. Мареева, А.Е. Друй, Л.Н. Шелихова, \\ А.И. Карачунский, М.А. Масчан
}

ФГБУ «Национальный медицинский исследовательский центр детской гематологии, онкологии и иммунологии им. Дмитрия Рогачева» Минздрава России, Москва

В данной статье представлено описание проведения аллогенной трансплантации гемопоэтических стволовых клеток (ТГСК) пациентке с метастатической формой альвеолярной рабдомиосаркомы. Представленный клинический случай имеет несколько особенностей манифестации заболевания, диагностики, а также выбора тактики терапии. Данное исследование одобрено независимым этическим комитетом и утверждено решением ученого совета ФГБУ «НМИЦ ДГОИ им. Дмитрия Рогачева» Минздрава России. За последние десятилетия не произошло существенного улучшения выживаемости пациентов с метастатическими формами злокачественных новообразований, в том числе больных с мягкотканными саркомами. Прогноз для таких пациентов остается крайне неблагоприятным, несмотря на интенсификацию химиотерапии и проведение лучевой терапии. Применение аутологичной ТГСК не привело к изменению в результатах лечения. В целях улучшения прогноза для пациентов группы очень высокого риска разрабатываются экспериментальные методы терапии, включающие иммунотерапевтические технологии. Данный случай описан ввиду применения нестандартного подхода терапии с получением положительного ответа в виде длительного контроля за болезнью и отсутствия системной прогрессии заболевания. Он показывает, что аллогенная ТГСК рассматривается как один из возможных перспективных методов для интенсификации терапии, главным образом, за счет существования эффекта «трансплантат против опухоли». Родители дали согласие на использование информации, в том числе фотографий ребенка, в научных исследованиях и публикациях.

Ключевые слова: аллогенная трансплантация гемопоэтических стволовых клеток, гаплоидентичная трансплантация гемопоэтических стволовых клеток, рабдомиосаркома, эфффект «трансплантат против опухоли», NK-клетки

Андреева Н.А. и соавт. Вопросы гематологии/онкологии и иммунопатологии в педиатрии. 2020; 19 (4): 94-101. DOl: 10.24287/1726-1708-2020-19-4-94-101

\section{Allogeneic hematopoietic stem cell transplantation for alveolar rhabdomyosarcoma: the first clinical experience of haploidentical transplantation}

N.A. Andreeva, E.A. Druy, Yu.M. Mareeva, A.E. Druy, L.N. Shelikhova, A.I. Karachunsky, M.A. Maschan

Dmitry Rogachev National Medical Research Center of Pediatric Hematology, Oncology and Immunology of Ministry of Healthcare of the Russian Federation, Moscow

This article describes the use of allogeneic hematopoietic stem cell transplantation (HSCT) for the treatment of a patient with metastatic alveolar rhabdomyosarcoma. The reported case is unusual in terms of its presentation, diagnosis, and choice of treatment. This study is supported by the Independent Ethics Committee and approved by the Academic Council of the Dmitry Rogachev National Medical Research Center of Pediatric Hematology, Oncology and Immunology. In the last decades, the survival rates of patients with metastatic malignant neoplasms, including those with soft-tissue sarcomas, have not improved significantly. The prognosis for these patients remains extremely poor despite the intensification of chemotherapy and the application of radiation therapy. The use of autologous HSCT has not brought about any positive changes in treatment outcomes. Experimental approaches to treatment, including immunotherapeutic techniques, aimed at improving the prognosis for very high-risk patients are currently under development. We chose to report this case because of the unconventional treatment approach that had helped to achieve long-term control over the disease and to prevent systemic progression. It demonstrates that allogeneic HSCT can be regarded as one of the promising options for treatment intensification mainly due to the "graftversus-tumour" effect. The patients' parents gave their consent to the use of their child's data, including photographs, for research purposes and in publications.

Key words: allogeneic hematopoietic stem cell transplantation, haploidentical hematopoietic stem cell transplantation, rhabdomyosarcoma, "graft-versus-tumour" effect, NK-cells

Andreeva N.A., et al. Pediatric Hematology/Oncology and Immunopathology. 2020; 19 (4): 94-101

DOl: $10.24287 / 1726-1708-2020-19-4-94-101$ 
а сегодняшний день прогноз для пациентов с метастатическими формами солидных опухолей остается неблагоприятным, несмотря на интенсивную химиотерапию (ХT) и проведение высокодозной ХТ (ВДХТ) с аутологичной трансплантацией гемопоэтических стволовых клеток (ауто-ТГСК) в 1-й линии терапии. Интенсификация режимов кондиционирования не привела к ожидаемому увеличению выживаемости, поскольку сопровождалась значительным повышением частоты посттрансплантационных осложнений и смертности, связанной с трансплантацией гемопоэтических стволовых клеток (ТГСК) [1].

В последнее время в индивидуальные схемы терапии при некоторых злокачественных новообразованиях включается аллогенная ТГСК (алло-ТГСК) $[2,3]$. Однако оценить ее эффективность при солидных опухолях затруднительно ввиду отсутствия рандомизированных исследований и малого числа пациентов, которым она проводится.

Первое сравнение ауто-ТГСК и алло-ТГСК при солидных опухолях проведено Европейской группой по трансплантации стволовых клеток крови и костного мозга в 1998 г. На тот момент по итогам сравнения пациентам с солидными опухолями не было рекомендовано проведение алло-ТГСК. Пациентам с неблагоприятным прогнозом (рецидив или прогрессия герминогенноклеточной опухоли, саркомы Юинга, нефробластомы; метастатическая форма саркомы Юинга, нефробластомы; неблагоприятная гистологическая форма нефробластомы, а также опухоли высокого риска: остеосаркома, медуллобластома и высокозлокачественная глиома) рекомендовалось проведение ауто-ТГСК ввиду ее меньшей токсичности [4]. С того времени изменились показания к проведению алло-ТГСК в связи с новыми научными открытиями и технологическими достижениями: лучшее понимание надлежащего периода для трансплантации, отбор пациентов, большая доступность доноров и улучшенные методы определения соответствия HLA, совершенствование технологии сбора клеток, улучшение поддерживающей терапии, в результате чего снизилась смертность, связанная с трансплантацией [5]. По последним рекомендациям Европейской группы трансплантации стволовых клеток крови и костного мозга, ауто-ТГСК рекомендуется всем пациентам с плохим прогнозом, а алло-ТГСК может проводиться в рамках исследовательских протоколов [6].

В онкогематологии алло-ТГСК признана одним из эффективных методов терапии $[2,7]$, главным образом благодаря существованию иммуноопосредованного эффекта «трансплантат против лейкемии» [8]. В 1984 г. М. Moscovitch и S. Salivan в экспериментах на мышах с аденокарциномой молочной железы показали существование эффректа «транс- плантат против опухоли» [9], реализация которого в последующем была с успехом применена в клинической практике. N.T. Ueno и соавт. (1998) наблюдали полную регрессию метастатических поражений у пациентки, страдающей раком молочной железы, после проведения алло-ТГСК. Также была показана зависимость ответа на проведение алло-ТГСК от развития реакции «трансплантат против хозяина» (РТПХ). На мышиных моделях была показана активация цитотоксических аллогенных Т-лимфоцитов во время развития РТПХ, которым в то время приписывались основные противоопухолевые свойства [10].

На сегодняшний день известно, что в достижении эффекта «трансплантат против опухоли» участвуют не только Т-лимфоциты [11]. В 2006 г. P. Lang и соавт. описали важнейший компонент аллогенного трансплантата - NK-клетки, которые играют значительную роль в противоопухолевом надзоре, и в сравнении с Т-клетками особенно эффективны против клеток со сниженной или отсутствующей экспрессией HLA 1-го класса [8], какими и являются клетки многих злокачественных новообразований [12]. Аллореактивные NK-клетки опосредуют снижение частоты развития РТПХ, риска отторжения трансплантата (путем лизиса Т-клеток хозяина), уменьшение частоты рецидива, улучшение приживления трансплантата и снижение частоты развития инфекционных осложнений $[2,13]$. В клинических исследованиях J.S. Miller, проведенных на группе пациентов с рефрактерным миелобластным лейкозом, показано, что NK-клетки играют непосредственную роль в антилейкемическом эффекте, кроме того, достижение полного ответа коррелирует с высоким содержанием циркулирующих донорских NK-клеток [14].

В экспериментах in vitro эффект NK-клеток усиливался при добавлении интерлейкина-2 (ИЛ-2), однако в исследованиях in vivo эффект стимуляции ИЛ-2 оказывался не столь значительным [8]. В настоящее время стали известны другие цитокины, которые используются для индукции пролиферации NK-клеток. Одним из таких цитокинов является ИЛ-15, который имеет структурную схожесть с ИЛ-2. На данный момент проведена I фаза клинических испытаний применения ИЛ-15 пролонгированного действия (ALT-803), в ходе которой показана его способность усиливать пролиферацию NK-клеток и CD8+-клеток in vivo [11]. Таким образом, сочетание алло-ТГСК с иммунотерапевтическими подходами может значительно повысить ее противоопухолевую эффективность. Данное исследование одобрено независимым этическим комитетом и утверждено решением ученого совета ФГБУ «НМИЦ ДГОИ им. Дмитрия Рогачева» Минздрава России. 


\section{ОПИСАНИЕ КЛИНИЧЕСКОГО СЛУЧАЯ}

Родители дали согласие на использование информации, в том числе фотографий ребенка, в научных исследованиях и публикациях. Манифестация заболевания у пациентки отмечена в возрасте 17 лет с астенического синдрома, проявлявшегося слабостью, периодическими головными болями. Проведение нейропротекторной терапии оказало кратковременный положительный эффект, уже через 3 нед были отмечены признаки анемиче- ского синдрома (бледность кожных покровов и слизистых), в связи с чем было проведено комплексное обследование в стационаре по месту жительства. Морфологическое и цитологическое исследования костного мозга выявили снижение клеточности и лейкемизацию костного мозга клетками, сходными по морфологии с клетками лимфомы Беркитта. По данным лучевых методов исследования обнаружены дегенеративно-дистрофические изменения костной системы, увеличение шейных и парааортальных лимфатических узлов, в связи с чем пациентка была направлена в НМИЦ ДГОИ им. Дмитрия Рогачева

Рисунок 1

Первичное морфологическое исследование костного мозга: тотальная метаплазия атипичными клетками, расположенными как разрозненно (А), так и образующими агломераты различной клеточности (Б). Автор изображений: М.М. Васильева, врач лабораторной диагностики

Figure 1

Initial morphological examination of the bone marrow: complete metaplasia: scattered atypical cells (A) and atypical cells forming agglomerates with various cellularity (Б). Image author: M.M. Vasilyeva, a clinical laboratory scientist
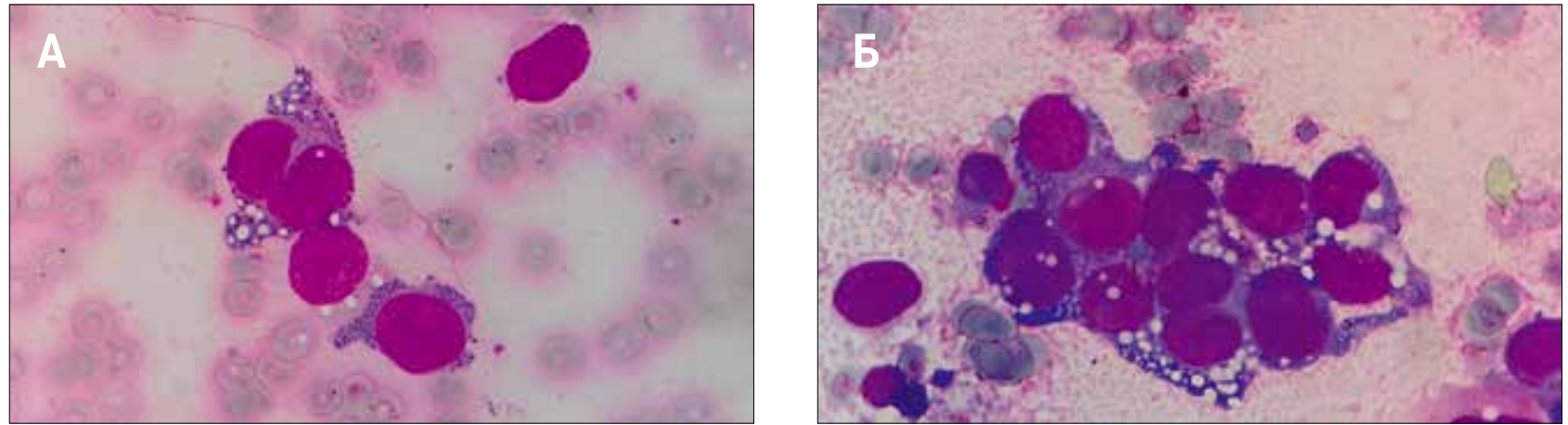

Рисунок 2

МРТ голеней с контрастным усилением (инициальное обследование): в мягких тканях нижней трети левой голени определяется опухолевое образование неправильной формы с нечеткими, неровными контурами, размером до 33 × 31 × 58 мм, интенсивно неоднородно накапливающее парамагнетик, инфильтрирующее прилежащие мышцы задней группы (А); в средней трети правой голени в медиальной головке икроножной мышцы определяется аналогичное опухолевое образование диаметром до 12 мм (Б); в проксимальных метадиафизах, верхних третях больше-и малоберцовой костей, дистальных диафизах бедренных костей, эпифизе левой большеберцовой кости определяются зоны диффузно измененного МР-сигнала, слабоинтенсивно накапливающие парамагнетик (B)

Figure 2

Magnetic resonance imaging of the lower legs with contrast enhancement (an initial investigation): in the soft tissues of the lower third of the left lower leg, there is a tumour mass of irregular shape with blurred uneven contours, up to $33 \times 31 \times 58 \mathrm{~mm}$ in size. The mass demonstrates intense inhomogeneous uptake of the paramagnetic agent and infiltrates the adjacent posterior lower leg muscles (A); in the middle third of the right lower leg (in the medial head of the gastrocnemius muscle), there is another similar tumour mass up to $12 \mathrm{~mm}$ in diameter ( $\mathrm{E}$ ); in the proximal metadiaphyses, the upper thirds of the tibias and the fibulas, the distal femoral diaphyses as well as in the epiphysis of the left tibia, there are areas with diffuse changes in signal intensity and low-intensity uptake of the paramagnetic agent $(B)$
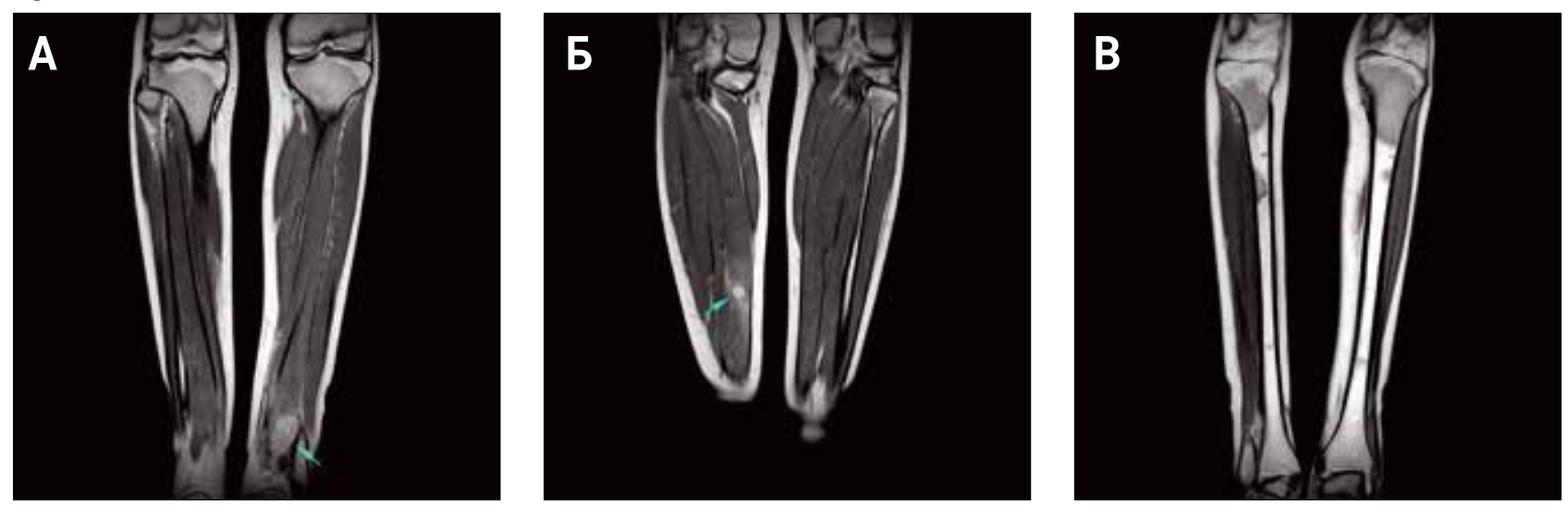
с предварительным диагнозом: лейкоз/лимфома Беркитта.

В НМИЦ ДГОИ им. Дмитрия Рогачева проведено повторное цитологическое исследование костного мозга (из 4 точек), по данным которого обнаружена его тотальная инфильтрация клетками с фенотипом CD45 $/ \mathrm{CD}^{2} 6^{+} / \mathrm{CD} 81^{+} / \mathrm{GD} 2^{+}$(рисунок 1). Цитоге- нетическое исследование костного мозга выявило наличие гиперплоидного клона с t(2;13). При исследовании методом флуоресцентной гибридизации in situ (fluorescence in situ hybridization, FISH) обнаружена перестройка гена forkhead box 01 (FOXO1). Магнитно-резонансная томография (MPT) (рисунок 2) и позитронно-эмиссионная томография, совме-

Рисунок 3

ПЭТ/КТ всего тела: А, Б - первичное исследование: определяются очаги повышенной метаболической активности в мягких тканях нижней трети левой голени и средней трети правой голени. Диффузно-очаговое повышенное накопление ${ }^{18} \mathrm{~F}$-фттордезоксиглюкозы в костях скелета, лимфатических узлах шеи и средостения, вероятнее всего, соответствует метастатическому поражению; В, Г - исследование на +30-е сутки от ауто-ТГСК: сохраняется очаговая метаболическая активность (меньшей интенсивности по сравнению с инициальным исследованием) в мягких тканях нижней трети левой голени (остаточная ткань образования). Накопление в верхней трети правой и левой большеберцовой кости (область биопсии); Д - исследование на +120-е сутки от ауто-ТГСК: сохраняется очаговая метаболическая активность в мягких тканях нижней трети левой голени меньшей интенсивности по сравнению с предыдущим исследованием (остаточная ткань образования). Автор изображений: Ю.Н. Ликарь, врач-радиолог

Figure 3

Whole-body positron emission tomography combined with computed tomography scans: A, 5 - an initial investigation: foci of increased metabolic activity in the soft tissues of the left lower leg (the lower third) and the right lower leg (the middle third). Increased diffuse and focal ${ }^{18} \mathrm{~F}$-fluorodeoxyglucose uptake in the skeletal bones and the cervical and mediastinal lymph nodes is most likely consistent with metastatic involvement; $B$, $\Gamma-$ an investigation performed on day +30 after autologous hematopoietic stem cell transplantation (HSCT): focal metabolic activity is still present (however less intense in comparison with the findings of the initial investigation) in the soft tissues of the lower third of the left lower leg (residual tumour tissue). 18F-FDG uptake in the upper thirds of the right and the left tibias (the biopsy sites); Д - an investigation performed on day +120 after autologous HSCT: focal metabolic activity is still present (however less intense in comparison with the findings of the initial investigation) in the soft tissues of the lower third of the left lower leg (residual tumour tissue). Image author: Yu.N. Likar, a radiologist

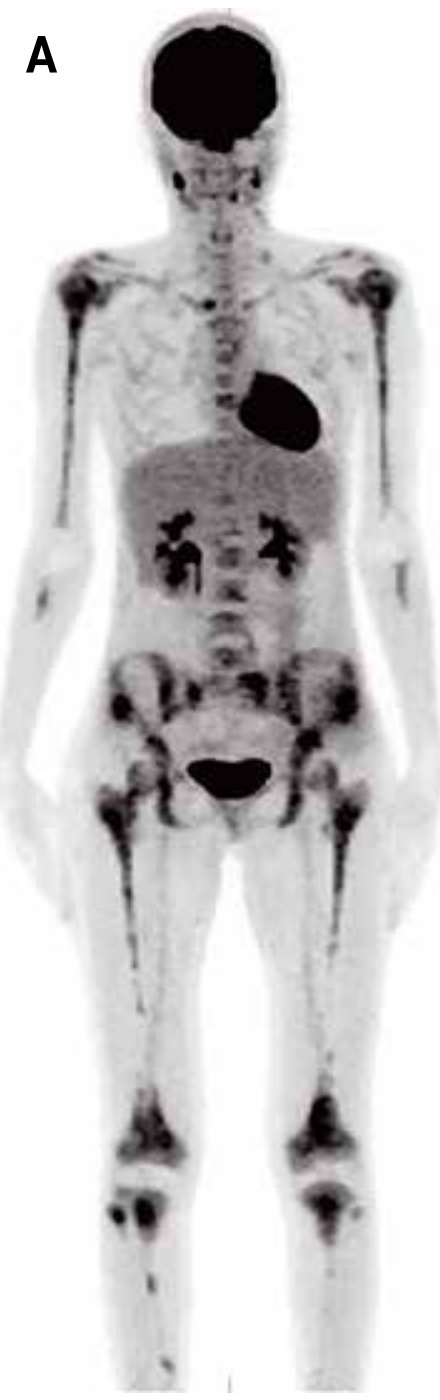

Б

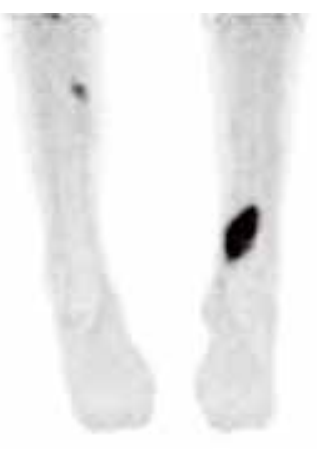

B

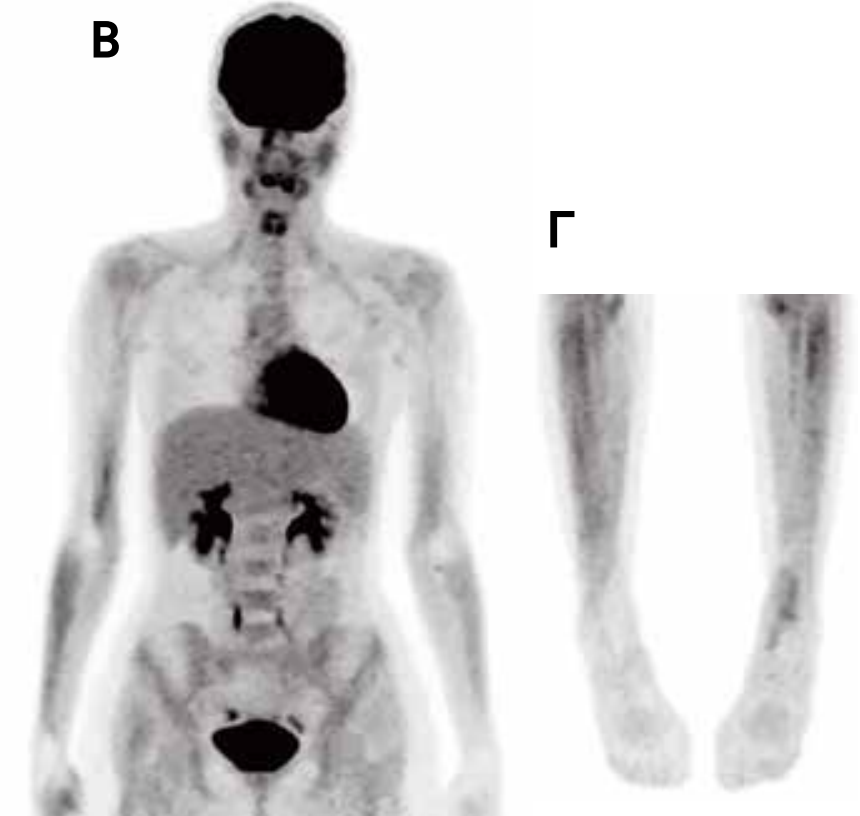

д

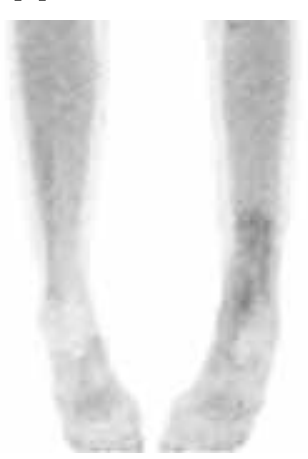


щенная с компьютерной томографией (ПЭТ/КТ) (рисунок ЗА, Б), позволили обнаружить образование мягких тканей в нижней трети левой голени (расцененное как первичный очаг) и в средней трети правой голени, а также множественное поражение бедренных, больше- и малоберцовых костей, лимфатических узлов шеи и средостения. Учитывая ограничения ПЭТ, связанные с неспособностью визуализации опухолей малых размеров, а также трудностями дифференцирования злокачественных заболеваний и воспалительных изменений, во всех случаях требуется подтверждение МРТ.

В целях гистологической верификации диагноза выполнена биопсия мягких тканей голени слева. По данным гистологического и иммуногистохимического исследований биоптата опухоли предварительный диагноз изменен, так как была верифицирована альвеолярная рабдомиосаркома (РMC).

Таким образом, пациентке был установлен диагноз: альвеолярная РМС нижней трети левой голени и средней трети правой голени Т2bNOM1, с метастатическим поражением костного мозга, костей скелета, лимфатических узлов шеи и средостения (IV группа по IRS). Поражение костного мозга было также подтверждено выявлением экспрессии химерного гена paired box gene 3 (PAX3)-FOXO1 в пунктатах из 4 подвздошных остей методом полимеразной цепной реакции (ПЦР) в режиме реального времени (рисунок 4). Проведена терапия по протоколу GPOH CWS-2009 для группы пациентов с инициальным метастатическим поражением по схеме CEVAIE. Молекулярная санация костного мозга зафиксирована после 3 курсов полиохимиотерапии (ПХТ). Локальный контроль проведен после 4 курсов индукционной ПХТ в объеме нерадикального удаления мягкотканной опухоли нижней трети левой голени. Гистологическое исследование выявило патоморфоз II степени.

После завершения программной терапии (суммарно 9 курсов ПХТ) зафиксирован очень хороший частичный ответ в виде нивелирования образования правой голени, сокращения образования левой голени на 90\%, количества многочисленных метастатических очагов в лимфатические узлы и кости скелета, а также сохранение молекулярной санации костного мозга по результатам ПЦР в режиме реального времени. Однако по данным проведенной ПЭТ/КТ метаболическая активность сохранялась в очагах в нижней трети левой голени и в эпифизах больше- и малоберцовых костей. При этом гистологическое исследование биоптатов очагов большеберцовых костей, визуализируемых на ПЭТ/KT, выявило патоморфоз IV степени. Согласно протоколу, пациентке был начат этап поддерживающей терапии по схеме трофосфамид/этопозид. По
Рисунок 4

Результат определения экспрессии химерного гена PAX3-FOХO1 методом ПЦР в режиме реального времени в образцах костного мозга, полученных во время инициальной диагностики (красные кривые, величина порогового цикла $\mathrm{Cq}=24,92)$ и на различных этапах терапии: во время блоков XT, перед и после аллогенной ТГСК (синие кривые, экспрессия химерного гена не определяется). Автор изображения: А.Е. Друй, врач клинической лабораторной диагностики

Figure 4

The results of a real-time polymerase chain reaction testing for PAX3-FOXO1 fusion gene on bone marrow samples obtained during the initial diagnostic examination (red curves, the cycle threshold value Cq is 24.29) and at different time points during the treatment: during chemotherapy cycles, before and after allogeneic HSCT (blue curves, no expression of the fusion gene). Image author: A.E. Druy, clinical laboratory diagnostics doctor

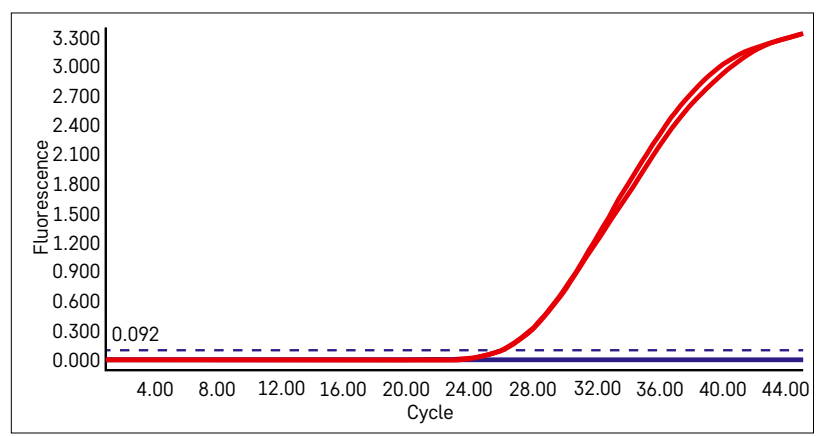

окончании 4 курсов поддерживающей терапии метаболическая активность определялась лишь в области очага в левой голени.

В связи с недостижением полного ответа на терапию, плохим прогнозом выживаемости в группе пациентов с распространенной альвеолярной РМС, отсутствием куративных возможностей системной цитотоксической терапии при развитии прогрессии, вероятность которой оставалась крайне высока, а также учитывая системный процесс заболевания и наличие химиочувствительной опухоли, было проведено обсуждение пациентки с предложением выполнения ТГСК. Применение ауто-ТГСК ограничилось отсутствием положительного эффекта в солидной онкологии. Предпочтение было отдано гаплоидентичной ТГСК (гапло-ТГСК), учитывая существование эффекта иммунотерапии, а также большой опыт проведения алло-ТГСК в нашем Центре с минимальными токсичными осложнениями в посттрансплантационном периоде.

Индивидуальный план лечения пациентки включал ТГСК от гаплоидентичного родственного донора (матери) с проведением TCR $\alpha \beta^{+} / \mathrm{CD} 19^{+}$-деплеции с последующей лучевой терапией (ЛТ) на оставшийся очаг в левой голени.

В режим кондиционирования входили флударабин, треосульфан, тиотепа. В качестве профилактики РТПХ применялись ритуксимаб, тоцилизумаб, абатацепт. Миелоинфузия проведена без осложнений. На +1-е сутки выполнено переливание донор- 
ских NK-клеток, предварительно инкубированных с ИЛ-12, ИЛ-15 и ИЛ-18.

В раннем посттрансплантационном периоде отмечались признаки РТПХ II степени в виде мелкопапулезной сыпи по всему телу, в связи с чем дополнительное введение NK-клеток не проводилось. Приживление лейкоцитарного ростка зафиксировано на +12-е сутки, тромбоцитарного - на +13-е сутки. Во всех контрольных точках (+30-е, +60-е, +90-е, +120-е сутки от алло-ТГСК) данных за прогрессирование основного заболевания не было, сохранялся полный донорский химеризм. По данным иммунофенотипического анализа периферической крови количество $\mathrm{NK}$-клеток на +30-е, +60-е, +90-е сутки составляло $0,261 \times 10^{6} /$ мл, 0,148 × 106/мл и 0,151 × 106/мл соответственно.

На контрольном исследовании ПЭТ/КТ, выполненном на +30-е сутки от алло-ТГСК, сохранялась очаговая метаболическая активность в мягких тканях левой голени (остаточная ткань образования), но в сравнении с исследованием, выполненным до аллоТГСК, интенсивность накопления была менее выраженной (рисунок 3В, Г).

C +69-х суток проводили конформную ЛТ на область опухоли нижней трети левой голени в режиме классического фракционирования с разовой очаговой дозой 1,8 Гр до суммарной очаговой дозы 50,4 Гр. После ЛТ выполнена МРТ голеней с контрастным усилением, где выявлена стабилизация процесса. В костном мозге сохранялась молекулярная ремиссия, достигнутая после 3-го курса индукционной ПХТ. По данным выполненной ПЭТ/ КТ на +120-е сутки от алло-ТГСК данных за метаболически активную опухоль получено не было (рисунок ЗД).

Но, к сожалению, через 9 мес после аллоТГСК была зафиксирована отрицательная динамика в виде появления пальпируемых образований в мягких тканях обоих бедер и в области мягких тканей левого плеча. По данным ПЭТ/КТ обнаружены множественные очаги метаболической активности в подкожно-жировой клетчатке грудной клетки, таза, верхних и нижних конечностей. Мягкотканное образование левого плеча было радикально удалено с последующим гистологическим исследованием, констатирована прогрессия основного заболевания. В целях поиска возможных мишеней для молекулярно-направленной терапии было предпринято высокопроизводительное секвенирование образца ДНК, выделенного из ткани опухоли на момент прогрессии, с помощью панели для целевого обогащения фрагментов ДНК Solid Tumor Solution Sophia Genetics (Швейцария). Результатом исследования стало выявление амплификации гена CDK4, достигающей 12 копий в клетке, других значимых аберраций обнаружено не было.

Учитывая прогрессию заболевания после предшествующего объема многокомпонентного химиотерапевтического лечения, а также имеющиеся данные об эффективности метрономной терапии у больных с метастатической РМС [15], пациентке начато лечение по схеме винорелбин/циклофосфамид на неопределенно длительный срок, который ограничивается прогрессией заболевания или развитием неприемлемой токсичности. В связи с отсутствием данных об эффективности ингибиторов CDK у пациентов с РМС, данная терапия не проводилась.

После 6-го курса паллиативной терапии отмечена очередная прогрессия заболевания с поражением паховых лимфатических узлов слева. Срок наблюдения за пациенткой составил 21 мес. На данный момент продолжается метрономная терапия (7 курсов) в условиях взрослой сети в связи с достижением пациенткой совершеннолетнего возраста.

\section{ОБСУЖДЕНИЕ РЕЗУЛЬТАТОВ ИССЛЕДОВАНИЯ}

РМС является самой частой мягкотканной саркомой у детей и подростков. Прогностически неблагоприятная форма опухоли - альвеолярная РМС составляет $32 \%$ среди пациентов моложе 20 лет. Наличие перестройки гена FOXO1 с образованием химерных конструкций с генами $P A X 3$ либо PAX7 (t(2;13)(q35;q14) и t(1;13)(p36;q14)) определяет крайне неблагоприятное течение заболевания. При этом выживаемость пациентов с альвеолярной РМС без перестроек FOXO1 достоверно не отличается от выживаемости больных, страдающих более благоприятной эмбриональной РМС. Хотя прогноз у пациентов с локализованным заболеванием значительно улучшился за последнее десятилетие, метастатическая форма, как и рецидивы заболевания, остается фатальной [16].

Для метастатической формы PMC 0. Oberlin и соавт. (американская и европейская кооперативная группа) определили прогностические критерии, учитывающие возраст, локализацию первичного очага, наличие поражения костей или костного мозга и общее количество метастатических областей (таблица). При этом гистологический тип, поражение регионарных лимфатических узлов и метастазы в легкие не оценивались, так как была продемонстрирована четкая взаимосвязь этих критериев с прогностическими признаками, включенными в схему стратификации [16]. Трехлетняя бессобытийная выживаемость (БСВ) для пациентов с метастатической РМС значительно отличалась в зависимости от наличия фракторов риска и составляла 50, 42, 18, 
12 и 5\% для пациентов с 0, 1, 2, 3 и 4 факторами риска соответственно. Среди данных групп отчетливо выделяются 2 подгруппы: пациенты с количеством неблагоприятных признаков $\leq 1$, что выявлено в $42 \%$ случаев, с 3-летней БСВ 44\%, и больные, имеющие $\geq 2$ фактора риска (58\% популяции), 3-летняя БСВ которых составляет 14\% [16]. Таким образом, пациенты, вошедшие во 2-ю подгруппу, должны рассматриваться как больные сверхвысокого риска, имеющие минимальные шансы на излечение при проведении стандартной терапии и нуждающиеся в использовании экспериментальных и инновационных методов лечения в 1-й линии терапии.

Выполнение ВДХТ, дополненной ауто-ТГСК, не привело к увеличению общей выживаемости (ОВ) у пациентов с РМС. В то же время имеются данные, что алло-ТГСК с/без клеточной терапии (инфузии донорских лимфоцитов) улучшает показатели выживаемости больных с различными солидными опухолями, что, возможно, обусловлено T-/NK-клеточным эффектом «трансплантат против опухоли» [2]. Эти наблюдения позволили предположить, что аллоТГСК в сочетании с клеточной иммунотерапией также может быть эффрективна у пациентов с РМС, поэтому нашей пациентке проводилось вливание NK-клеток.

В статье U. Thiel и соавт., опубликованной в 2013 г., проанализированы 30 пациентов с рецидивами и рефрактерным течением РМС в возрасте 4-28 лет, подвергшихся алло-ТГСК в связи с наличием метастатического распространения опухоли, отсутствием полного ответа после 1-й линии терапии или развитием рецидива заболевания. Трехлетняя ОВ составила лишь $20 \%$ (медиана - 12 мес), что сравнимо с эффектом ВДХТ с ауто-ТГСК [17]. Тем не менее была прослежена связь эффективности аллоТГСК с этапом ее проведения (в 1-й или последующих линиях терапии), а также с глубиной ответа на лечение, предшествующее трансплантации.

Описанная в настоящей статье пациентка подверглась гапло-ТГСК в 1-й линии терапии. По критериям 0. Oberlin больная принадлежит к группе сверхвысокого риска (> 2 факторов риска: неблагоприятный возраст, локализация, наличие поражения костей и костного мозга), соответственно, при проведении стандартной терапии шанс прожить 3 года и более не превышает $14 \%$. Несмотря на молекулярно-генетическую санацию костного мозга, достигнутую после 3 первых курсов ПХТ, регресс метастатических очагов к концу интенсивного этапа терапии не был полным, витальные опухолевые клетки в первичном очаге продолжали определяться, что позволило констатировать достижение очень хорошего частичного ответа. При этом персистенция остаточной опухоли в организме определяла чрезвычайно высокий риск развития прогрессии заболевания после завершения программной терапии. Это обусловило необходимость поиска альтернативных лечебных стратегий на этапе консолидации. В данном случае технологией выбора стала гаплоТГСК, которая в сочетании с клеточной иммунотерапией позволила добиться продолжающегося сокращения остаточного компонента опухоли и системного контроля над заболеванием, продлившегося в течение 9 мес. Однако, учитывая сохранение витальной опухоли в организме, прогрессия заболевания оказалась неизбежной. В целях контроля за системной прогрессией пациентке назначена метрономная терапия. На момент написания статьи пациентка в течение 8 мес получала метрономную терапию без клинических признаков прогрессии заболевания. Срок наблюдения от проведения аллоТГСК составляет 21 мес.

\section{ЗАКЛЮЧЕНИЕ}

Эффективность алло-ТГСК при солидных опухолях продолжает обсуждаться. Углубление понимания механизмов иммунного ответа против опухоли при выполнении ТГСК и новые описания успешно проведенных алло-ТГСК у больных с солидными опухолями позволяют рассматривать этот метод

\section{Таблица}

Факторы риска при метастатической форме PMC (0. Oberlin)

Table

Risk factors in metastatic rhabdomyosarcomas (0. Oberlin)

\begin{tabular}{|c|c|c|}
\hline \multirow{2}{*}{$\begin{array}{l}\text { Параметр } \\
\text { Parameter }\end{array}$} & \multicolumn{2}{|l|}{$\begin{array}{c}\text { Критерии } \\
\text { Criteria }\end{array}$} \\
\hline & $\begin{array}{l}\text { благоприятные } \\
\text { favourable }\end{array}$ & $\begin{array}{c}\text { неблагоприятные } \\
\text { unfavourable }\end{array}$ \\
\hline $\begin{array}{l}\text { Возраст, годы } \\
\text { Age, years }\end{array}$ & $1-9$ & $\begin{array}{l}\leq 1 \text { или } \geq 10 \\
\leq 1 \text { or } \geq 10\end{array}$ \\
\hline $\begin{array}{l}\text { Локализация } \\
\text { Site }\end{array}$ & $\begin{array}{c}\text { Орбита, непараменингеальная, параменингеальная, } \\
\text { мочевой пузырь/простата, паратестикулярная/ } \\
\text { влагалище } \\
\text { Orbit, non-parameningeal, parameningeal, bladder/prostate, } \\
\text { paratesticular/vagina }\end{array}$ & $\begin{array}{l}\text { Конечности и др. } \\
\text { Limbs and other sites }\end{array}$ \\
\hline $\begin{array}{l}\text { Поражение костей/костного мозга } \\
\text { Bone or bone marrow involvement }\end{array}$ & $\begin{array}{c}\text { Het } \\
\text { No } \\
\end{array}$ & $\begin{array}{l}\text { Да } \\
\text { Yes }\end{array}$ \\
\hline $\begin{array}{l}\text { Количество метастатических областей } \\
\text { Number of metastatic sites }\end{array}$ & $\leq 2$ & $\geq 3$ \\
\hline
\end{tabular}


лечения как один из возможных для интенсификации терапии у пациентов с РМС с плохим прогнозом.

В данной статье описан случай применения алло-ТГСК у пациентки с крайне неблагоприятным прогнозом. Применение иммунотерапии наряду с метрономной терапией позволило длительно контролировать заболевание. Более того, новые технологии проведения алло-ТГСК позволяют выполнить трансплантацию без выраженной токсичности в посттрансплантационном периоде. Однако при каких обстоятельствах она будет обоснованной удастся выяснить только в рамках проспективных контролируемых клинических исследований. Данное наблюдение может быть основой для проведения исследования гапло-ТГСК для больных с саркомами.

\section{ИСТОЧНИК ФИНАНСИРОВАНИЯ}

Не указан.

\section{КОНФЛИКТ ИНТЕРЕСОВ}

Авторы статьи подтвердили отсутствие консрликта интересов, о котором необходимо сообщить.

ORCID

Andreeva N.A. ORCID: https://orcid.org/0000-0001-5626-218X

Druy E.A. ORCID: https://orcid.org/0000-0003-0899-7266

Mareeva Yu.M. ORCID: https://orcid.org/0000-0003-0652-6049

Druy A.E. ORCID: https://orcid.org/0000-0003-1308-8622

Shelikhova L.N. ORCID: https://orcid.org/0000-0003-0520-5630

Karachunsky A.I. ORCID: https://orcid.org/0000-0002-9300-198X

Maschan M.A. ORCID: https://orcid.org/0000-0003-1735-0093

\section{Литература}

1. Schlegel P., Feuchtinger T., NitschkeGérard C. Favorable NK cell activity after haploidentical hematopoietic stem cell transplantation in stage IV relapsed Ewing's sarcoma patients. Bone Marrow Transplant 2015; 50 (2): 72-6. DOI: 10.1038/bmt.2015.100

2. De Casterléa I., Billiaua A.D., Sprangers B. Recipient and donor cells in the graft-versus-solid tumor effect: It takes two to tango. Blood Rev 2018; 32 (6): 449-56. DOl: 10.1016/j.blre.2018.04.002

3. Blaise D., Bregni M. Allogeneic stem cell transplantation for solid tumors: which way forward? Biol Blood Marrow Transplant 2007; 13: 73-5. DOI: 10.1016/j. bbmt.2006.10.022

4. Goldman J.M., Schmitz N., Neithammer D., Gratwohl A. Allogeneic and autologous transplantation for haematological diseases, solid tumours and immune disorders: current practice in Europe in 1998. Bone Marrow Transplant 1998; 21 (1): 1-7. DOl: $10.1038 /$ sj.bmt.1701089

5. Goldman J.M., Horowitz M.M. The international bone marrow transplant registry. Int J Hematol 2002; 76 (1): 393-7. DOI: 10.1007/BF03165291

6. Ljungman P., Bregni M., Brune M., Cornelissen J., de Witte T., Dini G., et al. Allogeneic and autologous transplantation for haematological diseases, solid tumours and immune disorders: current practice in Europe 2009. Bone Marrow Transplant 2010; 45 (2): 219-34. DOI: 10.1038/ bmt.2009.141

7. Carnevale-Schianca F., Ricchiardi A., Capaldi A., Bucci A.R., Grignani G.,
Rota-Scalabrini D., et al. Allogeneic Hemopoietic stem cell transplantation in solid tumors. Transplantation Proc 2005; 37 (6): 2664-6. DOl: 10.1016/j.transproceed.2005.06.050

8. Lang P., Pfeiffer M., Müller I., Schumm M., Ebinger M., Koscielniak E., et al. Haploidentical stem cell transplantation in patients with pediatric solid tumors: preliminary results of a pilot study and analysis of graft versus tumor effects. Klin Padiatr 2006; 218 (6): 321-6. DOI: 10.1055/s-2006-942256

9. Moscovitch M., Slavin S. Anti-tumor effects of allogeneic bone marrow transplantation in (NZB X NZW) F1 hybrids with spontaneous lymphosarcoma. J Immunol 1984; 132 (2): 997-1000.

10. Ueno N.T., Rondon G., Mirza N.Q., Geisler D.K., Anderlini P., Giralt S.A., et al. Allogeneic peripheral-blood progenitor-cell transplantation for poor-risk patients with metastatic breast cancer. J Clin Oncol 1998; 16 (3): 986-93. DOI: 10.1200/ JC0.1998.16.3.986

11. Margolin K., Morishima C., Velcheti V., Miller J.S., Lee S.M., Silk A.W., et al. Phase I Trial of ALT-803, A Novel Recombinant IL15 Complex, in Patients with Advanced Solid Tumors. Clin Cancer Res 2018; 24 (22): 5552-61. DOI: 10.1158/1078-0432. CCR-18-0945

12. Haworth K.B., Leddon J.L., Chen C.-Y., Horwitz E.M., Mackall C.L., Cripe T.P. Going back to class I: MHC and immunotherapies for childhood cancer. Pediatr Blood Cancer 2015; 62 (4): 571-6. DOI: 10.1002/pbc.25359
13. Lundqvist A., Childs R. Allogeneic hematopoietic cell transplantation as immunotherapy for solid tumors current status and future directions. J Immunother 2005; 28 (4): 281-8. DOI: 10.1002/pbc.25359

14. Miller J.S., Soignier Y., Panoskaltsis-Mortari A., McNearney S.A., Yun G.H., Fautsch S.K., et al. Successful adoptive transfer and in vivo expansion of human haploidentical NK cells in patients with cancer. Blood 2005; 105 (8): 3051-7. DOl: 10.1182/blood-2004-07-2974

15. Minard-Colin V., Ichante J.L., Nguyen L., Paci A., Orbach D., Bergeron C., et al. Phase II study of vinorelbine and continuous low doses cyclophosphamide in children and young adults with a relapsed or refractory malignant solid tumour: good tolerance profile and efficacy in rhabdomyosarcoma - a report from the Société Française des Cancers et leucémies de l'Enfant et de l'adolescent (SFCE). Eur J Cancer 2012; 48 (15): 2409-16. DOI: 10.1016/j.ejca.2012.04.012

16. Oberlin O., Rey A., Lyden E., Bisogno G., Stevens M.C., Meyer W.H., et al. Prognostic factors in metastatic rhabdomyosarcomas: results of a pooled analysis from United States and European cooperative groups. J Clin Oncol 2008; 26 (14): 23849. DOI: $10.1200 / J C 0.2007 .14 .7207$

17. Thiel U., Koscielniak E., Blaeschke F., Grunewald T.G.P., Badoglio M., Diaz M.A., et al. Allogeneic stem cell transplantation for patients with advanced rhabdomyosarcoma: a retrospective assessment. $\mathrm{Br}$ J Cancer 2013; 109 (10): 2523-32. DOI: 10.1038/bjc.2013.630 